\title{
Appendicular Endometriosis: A Rare Entity
}

\author{
Rahman $S^{1}$, Sayeed $S^{2}$, Ahmed $N^{3}$
}

Conflict of Interest: None

Received: $27-09-2017$

Accepted: 05-11-2017

www.banglajol.info/index.php/JSSMC

Key words:

Endometriosis,

Appendicitis

\begin{abstract}
s
A patient having recurrent right sided lower abdominal pain was admitted as with appendicitis. Laparoscopic appendicectomy was done. On histopatholigical examination it was found to be Endometriosis.
\end{abstract}

[J Shaheed Suhrawardy Med Coll 2017; 9(2): 83-84] DOI: http://dx.doi.org/10.3329/jssmc.v9i2.37269

\section{Introduction:}

Endometriosis is a condition in which the layer of tissue that normally covers the inside of the uterus grows outside of it. Gastrointestinal endometriosis (GE) is observed in 3$37 \%$ of all endometriosis cases. But appendicular endometriosis (AE) accounts for only about $3 \%$ of GE \& $<1 \%$ of total endometriosis cases ${ }^{1-3}$. AE may not only cause symptoms of acute \& chronic appendicitis but also cyclic right lower quadrant pain, melaena, lower intestinal haemorrhage, caecal intussusception \& intestinal perforation ${ }^{3}$.

In this case, our patient underwent laparoscopy with presumed diagnosis as acute appendicitis. Appendicectomy was done and a histopathological examination of the retrieved specimen revealed appendicular endometriosis.

\section{Case report:}

Mrs. X, a 40 years old patient, came in surgery outpatient department with right lower quadrant pain for 12 hours. The pain was followed by vomiting and loose motion. She was a housewife with two children delivered by vaginal route. The pain was not associated with her menstruation. She had a regular menstrual cycle \& practiced barrier contraceptive method. Her medical history was

1. Dr. Sumana Rahman, Junior Consultant, Department of Obstetrics and Gynaecology, Government Employees' Hospital, Fulbaria, Dhaka

2. Dr. Shovon Sayeed, Junior consultant, Department of Surgery, Government Employees' hospital Fulbaria, Dhaka

3. Dr. Nadim Ahmed, Senior Consultant, Department of Surgery, Shaheed Suhrawardy Medical College and Hospital, Dhaka

Correspondence to: Dr. Sumana Rahman, Junior Consultant, Department of Obstetrics and Gynaecology, Government Employees' Hospital, Fulbaria, Dhaka. Email : sumanarahman0@gmail.com unremarkable. The vital findings were stable with a normal body temperature. A physical examination revealed severe abdominal tenderness \& guarding in the right lower quadrant. On ultrasonography the findings were nonsignificant except for a small cyst $2.1 \times 2.0 \mathrm{~cm}$ in right adnexa. Blood count revealed neutrophilic leukocytosis. Urine analysis showed no pyuria or haematuria. Urine for pregnancy test was negative. The findings from physical examination \& investigations were consistent with acute appendicitis. Laparoscopy was arranged and appendicectomy was done. The right tuboovarian structures were normal. The surgery was terminated upon detection of no further pathology. The histopathological evaluation revealed endometriosis containing endometrial glands \& stroma in muscularis propria of the wall of appendix. Infiltration of chronic inflammatory cells were present. Her serum level of CA-125 was done later, which was found normal.

\section{Discussion:}

Endometriosis is a condition in which the layer of tissue that normally covers the inside of the uterus grows outside of $\mathrm{it}^{4}$.It is a common benign gynaeclogic disorder \& has been divided into internal \& external forms according to localization. It is called internal endometriosis when the endometrial tissue is found within the uterine muscles. External endometriosis is commonly found in genital organs \& the pelvic peritoneum, although it may be seen in the gastrointestinal system, omentum, mesentery, liver $\&$ surgical scars, but rarely in other organs ${ }^{5}$. Various authors have estimated that upto $15 \%$ of all reproductive age women $\& 1 / 3$ of infertile women have endometriosis. The precise etiology that completely explains the cause \& pathogenesis of endometriosis is unknown. Two main hypothesis have been proposed to explain its cause: one suggests that multipotential mesenchymal cells may 
undergo metaplasia into endometriosis under proper circumstances; the other hypothesis states that viable endometrial cells are implanted from retrograde menstruation through the fallopian tubes ${ }^{6}$.

The most common sites where endometriosis occurs are the ovaries $(60-75 \%)$, uterosacral ligaments(30-65\%), culde-sac(20-30\%), gastrointestinal tract(3-37\%), ureters(1$2 \%$ ), urinary bladder $(<1 \%) \&$ scar tissue $(<1 \%)^{7}$. Among GIT the rectosigmoid region( $(72 \%)$ is the commonest site, followed by the recto-vaginal septum(13\%), small bowel( $(7 \%)$, caecum( $4 \%) \&$ appendix $(3 \%)^{3,8}$.

Acute appendicitis is one of the most common acute surgical conditions of the abdomen $\&$ appendicectomy is one of the most frequently performed operations worldwide. Endometriosis affecting the ileocaecal appendix is rare. The clinical picture is complex \& may be categorized into groups according to the symptoms: asymptomatic patients, those with acute appendicitis, patients presenting with invagination of appendix, those with appendicular perforation \& also the ones with atypical symptoms (abdominal pain, nausea $\&$ melaena) ${ }^{5}$. Also the chronic obstruction of intestinal lumen may lead to the formation of mucocele or inflammatory periappendicular mass, which is hard to distinguish from neoplasm ${ }^{8}$.

Diagnostic options as a patients medical history, physical examination findings, blood tests (CA-125), colonoscopy, transvaginal or transrectal ultrasonography, barium enema, computed tomography and magnetic resonance imaging can be utilized to make an endometriosis diagnosis. However, none of these options can establish a definitive diagnosis of gastrointestinal endometriosis. A definitive diagnosis is often made by laparoscopy or laparotomy with a biopsy \& is particularly useful in patient with intestinal implants. Histopathological evaluations, in terms of both the definitive \& differential diagnosis, are of paramount importance in diagnosing appendiceal endometriosis ${ }^{7}$. The mucosa of appendix is mostly unaffected, whereas glandular tissue, endometrial stroma $\&$ hemorragica are seen in the muscular \& seromuscular layer in two-thirds of patients, and solely in the serosal layer in one-third of patients.
Some patients with endometriosis are completely asymptomatic \& the implants are found incidentally at the time of surgery for other reasons. Additional medical therapy should be considered following an appendicectomy in cases with symptomatic secondary appendicular endometriosis ${ }^{9}$. In our case we gave Danazole for 3 months after the operation.

\section{Conclusion:}

Appendicular endometriosis is an unusual histopathological finding. A preoperative diagnosis is difficult. This condition should be considered when women of child bearing age present with clinical symptoms of acute appendicitis. The accurate incidence of endometriosis may be increased if every specimen of appendicectomy in female is sent for histopathological examination.

\section{References:}

1. Akagi T, Yamamoto S, Kobayashi Y, Fujita S, Akasu T, Moriya $\mathrm{y}$, et al. A case of endometriosis of the appendix with adhesion to right ovarian cyst presenting as intussusception of a mucocele of the appendix. Surgical Laparoscopy, Endoscopy and Percutaneous Techniques 2008; 18[6]: 622-5.

2. Tumay V, Ozturk E, Ozturk H; Yilmazlar T. Appendiceal endometriosis mimicking acute appendicitis. Acta Chirurgica Belgica 2006; 106[6]: 712-3.

3. Gon S, Barui GN, Majumder B, Baig S J. Endometriosis of the appendix: a diagnostic dilemma. Indian Journal of Surgery 2010; 72[1]: 315 .

4. Schenken RS. Endometriosis. In: Scott JR, Disaia PJ, Ham CB, Spellacy WN, editors. Dan forth's obstetrics and gynaecology. Philadelphia: Lippincott-Raven Publishers; 1999. P. 669

5. H. Uncu, D. Taner. Appendiceal endometriosis: two case reports. Archives of Gynaecology and Obstetrics, 278[3] ; 2008: p 273-275.

6. S. Akbulut, M. M. Sevinc, S. Bakir, B. Cakabay, A. Sezgin. Scar endometriosis in the abdominal wall: a predictable condition for experienced surgeons. Acta Chirurgica Belgica, 110 [3]; 2010, p. 303-307.

7. S.A Salati, Raza. Endometriosis: a rare cause of appendicitis. Journal of College of Physicians and Surgeons Pakistan, 21[5]; 2011, p. 304-305.

8. Snyder MJ, Endometriosis. In: Wolff BG, Fleshman JW, Beck DE, Pemberton JH, Wexner, SD, editors. The ASCRS Textbook of colon and rectum surgery. New York: Springer; 2007. P. 308-19.

9. Gustofson RL, Kim N, Liu S, Stratton P. Endometriosis and the appendix: a case series and comprehensive review of the literature. Fertility and Sterility 2006; 86[2]: 298-303. 